\title{
Isolamento e seleção de fungos produtores de lipases com base na atividade lipásica e no potencial hidrolítico sobre óleo comestível de soja e escuma de caixa de gordura
}

\author{
Isolation and selection of lipase-producing fungi based on lipase \\ activity and hydrolytic potential on soybean oil and grease trap scum \\ Celson Rodrigues', Sérvio Túlio Cassini², Paulo Wagner Antunes ${ }^{3}$, \\ Regina Pinho Keller ${ }^{4}$, Ricardo Franci Gonçalves ${ }^{5}$
}

\begin{abstract}
RESUMO
O uso de biomassa fúngica como biocatalisadora lipásica representa uma atraente abordagem para o tratamento de águas residuais oleosas e produção de biodiesel, a partir de óleos e graxas residuais, devido à sua maior estabilidade, possibilidade de reuso e baixo custo. Neste trabalho foram obtidos cem isolados de fungos, a partir de escumas de caixa de gordura e esgoto, solo e tecidos necrosados de plantas e insetos, que foram avaliados quanto ao crescimento e à atividade lipásica, no meio de cultura básico, para atividade lipásica extracelular, e meio mineral mínimo + óleo de soja + rodamina, para atividade lipásica intracelular, com resposta positiva e diferenciada de 66 deles, inclusos como pertencentes aos gêneros Aspergillus, Beauveria, Botrytis, Cladosporium, Colletotrichum, Fusarium, Geotrichum, Penicillium, Rhizomucor e Verticillium. Na sequência, o potencial hidrolítico dos isolados Penicillium sp. FOO2 e Rhizomucor sp. F018 foi avaliado sobre óleo de soja comestível e escuma de caixa de gordura, em fermentação em estado sólido, através da quantificação das variáveis: produção de $\mathrm{CO}_{2}$, remoção do teor de óleos e graxas e crescimento da biomassa. Os resultados confirmaram a elevada atividade lipásica extracelular de Penicillium sp. FOO2 e a elevada atividade lipásica intracelular de Rhizomucor sp. FO18. Portanto, o isolado Rhizomucor sp. FO18 mostrou potencial para utilização em pesquisas futuras, na forma de células integrais lipásicas, para o tratamento de águas residuais oleosas e como biocatalisador na produção de biodiesel a partir de resíduos oleosos.
\end{abstract}

Palavras-chave: isolamento e seleção; fungos; atividade lipásica; hidrólise; óleo de soja; escuma de caixa de gordura.

\begin{abstract}
The use of fungal biomass as a lipase biocatalyst represents an attractive approach for the treatment of oil wastewater and production of biodiesel from oil and residual grease, due to its greater stability, possibility of reuse, and lower cost. In this work, a hundred filamentous fungi were isolated from grease trap and sewage scums, soil, and necrotized plants and insects tissues. The isolates were assessed for growth and lipase activity in the culture basic medium, for extracellular lipase activity, and mineral medium minimum + soybean oil + rhodamine, for intracellular lipase activity, with positive and differential response of 66 of them, including those belonging to the genera Aspergillus, Beauveria, Botrytis, Cladosporium, Colletotrichum, Fusarium, Geotrichum, Penicillium, Rhizomucor, and Verticillium. Following, previously selected Penicillium sp FOO2 and Rhizomucor sp. FO18 isolates were evaluated in solidstate fermentation, for the hydrolytic potential on edible soybean oil and grease trap scum, quantified by: $\mathrm{CO}_{2}$ production removal of the content of oils and greases, and biomass growth. Results confirmed the high extracellular lipase-activity of Penicillium sp. FOO2 and the high intracellular lipase activity of Rhizomucor sp. FO18. Therefore, the isolated Rhizomucor sp. ECG18 showed potential for use in future research, in the form of whole-cell lipases, for oily wastewater treatment, and as a biocatalyst in the production of biodiesel from oil residues.
\end{abstract}

Keywords: isolation and selection; fungi; lipase activity; hydrolysis; soybean oil; grease trap scum.

Doutor em Engenharia Ambiental pela Universidade Federal do Espírito Santo (UFES). Professor do Departamento de Engenharia Ambiental da UFES - Vitória (ES), Brasil. 2Doutor em Microbiologia Ambiental pela North Carolina State University (NCSU). Professor do Departamento de Engenharia Ambiental da UFES - Vitória (ES), Brasil. ${ }^{3}$ Doutor em Engenharia Ambiental pela UFES. Pesquisador do Laboratório de Saneamento da UFES - Vitória (ES), Brasil.

${ }^{4}$ Doutor em Engenharia do Tratamento de Águas pelo Institut National Des Sciences Appliquées Toulouse (INSAT). Professor do Departamento de Engenharia Ambiental da UFES - Vitória (ES), Brasil.

${ }^{5}$ Doutora em Microbiologia Ambiental pela University of Ottawa (UO). Professora do Departamento de Engenharia Ambiental da UFES - Vitória (ES), Brasil. Endereço para correspondência: Celson Rodrigues - Rua Durval Loureiro Nogueira, 111 - Jardim Camburi - 29090-650 - Vitória (ES), Brasil - E-mail: celsonrodrigues@yahoo.com.br Recebido: 06/10/14 - Aceito: 21/12/15 - Reg. ABES: 141401 


\section{INTRODUÇÃO}

Lipídeos (gorduras, óleos e graxas) encontram-se presentes em águas residuais municipais e em elevadas concentrações naquelas oriundas de algumas indústrias, como em refinarias de óleos comestíveis, frigoríficos, curtumes e indústrias de laticínios, resultando em prejuízos à eficiência dos sistemas de tratamento e elevação dos custos (MENDES et al., 2005, CAMMAROTA \& FREIRE, 2006; ALBERTON et al., 2010).

Técnicas para melhorar a eficiência dos sistemas de tratamento de águas residuais oleosas incluem instalação de caixas de gordura ou flotadores, tratamentos com adição de álcalis ou enzimas específicas como as hidrolases, principalmente as lipases. A adição dessas enzimas pode aumentar significativamente a eficiência dos processos de tratamento, reduzindo os impactos ambientais gerados sobre os recursos hídricos, considerados atualmente como um recurso natural limitado, dotado de valor econômico (MENDES et al., 2005). Em contrapartida, triglicerídeos residuais oriundos de processos de saneamento ambiental podem constituir matéria prima de reduzido custo para a geração de biodiesel (HAMA \& KONDO, 2013).

As lipases (triacilglicerol acil hidrolases, E.C. 3.1.1.3) atuam na interface orgânica-aquosa catalisando as reações de hidrólise de triglicerídeos e, em presença de baixas concentrações de água atuam em reações de esterificação, transesterificação ou interesterificação, com amplo leque de utilizações, dentre elas no pré-tratamento hidrolítico de efluentes oleosos e na etanólise enzimática de óleos e graxas residuais para a produção de biodiesel (HASAN; SHAH; HAMEED, 2009; NAGARAJAN, 2012; AGUIEIRAS; CAVALCANTI-OLIVEIRA; FREIRE, 2015).

Apesar da ampla utilização e/ou potencial para tal, as lipases industriais comercializadas possuem preço elevado, o principal fator limitante para expansão de sua utilização em vários segmentos das cadeias produtivas e de serviços, como os de produção de biocombustíveis e de saneamento ambiental. Esse fato justifica crescentes investimentos em pesquisas para o isolamento e a seleção de novas fontes microbianas, como os fungos, com potencial natural para a elevada produção dessas enzimas, de forma técnica e economicamente viável (GRIEBELER et al., 2011; SINGH \& MUKHOPADHYAY, 2012).

Os fungos, dentre os microrganismos, são fontes preferenciais de lipases para uso comercial, pois essas são geralmente extracelulares, facilitando a sua extração do meio fermentado; também por serem eles considerados microrganismos seguros para a manipulação, além da expectativa crescente do seu emprego como biocatalizadores na forma de células integrais lipásicas, imobilizadas ou não, simplificando e reduzindo o custo dos processos reacionais nos quais são utilizados (RODRIGUES \& FERNANDEZ-LAFUENTE, 2010; SINGH \& MUKHOPADHYAY, 2012; ANDRADE et al., 2014; CARVALHO et. al., 2015).
Fungos produtores de lipases podem ser isolados a partir de fontes diversas como: resíduos industriais e domésticos oleosos e ou gordurosos, solos contaminados com óleos e graxas, plantas e animais vivos ou mortos, sementes oleaginosas e outras (COLEN; JUNQUEIRA; MORAES-SANTOS, 2006; GRIEBELER et al., 2011; TURKI, 2013). Durante o processo de seleção quanto à atividade lipásica e/ou hidrolítica, embora o cultivo submerso seja comumente utilizado, no caso específico dos fungos filamentosos é importante considerar que essa forma de cultivo pode levar à alteração da expressão gênica para características fenotípicas como o crescimento, a produção de metabólitos secundários e a atividade enzimática, e que, por outro lado, fungos desenvolvidos em processos fermentativos sólidos contam com condições similares àquelas do seu habitat natural, favorecendo a produção e obtenção de maiores quantidades de enzimas (GRIEBELER et al., 2011; NAGARAJAN, 2012).

O objetivo deste trabalho foi o isolamento e a seleção de fungos filamentosos produtores de lipases, a partir de resíduos oleosos do saneamento ambiental e outras fontes, com utilização de meios de cultura sólidos indicadores de atividade lipásica e via hidrólise de óleo comestível de soja e de escuma de caixa de gordura, em processo de fermentação em estado sólido conduzido em condições de laboratório.

\section{METODOLOGIA}

Os ensaios experimentais foram conduzidos no Laboratório de Saneamento (LABSAN), pertencente ao Departamento de Engenharia Ambiental do Centro Tecnológico da Universidade Federal do Espírito Santo (UFES), localizado em Vitória, Espírito Santo.

\section{Isolamento, pré-seleção e identificação de fungos produtores de lipases}

$\mathrm{O}$ isolamento dos fungos filamentosos ocorreu a partir de tecidos de banana (Musa acuminata), mamão (Carica papaya) e oiti (Licania tomentosa), necrosados por atividade de fungos fitopatogênicos, bem como de formiga saúva (Atta capiguara), lagarta do cartucho do milho (Spodoptera frugiperda), broca do cafeeiro (Hypothenemus hampei), cigarrinha da cana-de-açúcar (Mahanarva posticata) e cigarrinha das pastagens (Deois flavopicta), necrosados por atividade patogênica de fungos.

Nessa etapa foram utilizados o meio batata-dextrose-ágar (BDA), com o pH corrigido para 6,0 ( $\mathrm{NaOH} 0,1 \mathrm{M})$, e o método de isolamento direto, conforme Menezes e Assis (2004), que consistiu na transferência de esporos fúngicos da superfície dos tecidos vegetais necrosados ou da superfície necrosada dos insetos para placas de Petri contendo $20 \mathrm{~mL}$ do meio BDA, acrescido de $1 \mathrm{mg}$ de sulfato de estreptomicina e $1 \mathrm{mg}$ de cloranfenicol. As placas assim preparadas foram incubadas durante $96 \mathrm{~h}$, à temperatura de $28^{\circ} \mathrm{C}$, no escuro. 
Decorrido o período de incubação, as colônias fúngicas com características morfológicas macroscópicas diferentes foram repicadas sucessivamente até o completo isolamento. Os isolados obtidos foram transferidos para tubos de ensaio com BDA e esses incubados conforme descrito anteriormente. Após a incubação os tubos foram armazenados em geladeira a $5^{\circ} \mathrm{C}$, para posterior identificação e avaliação do crescimento e das atividades lipásica e hidrolítica.

$\mathrm{O}$ isolamento de fungos filamentosos ocorreu a partir de amostras de solo, coletadas em um pomar de mangueiras localizado na UFES, e de resíduos oleosos do saneamento ambiental constituídos por escuma de esgoto sanitário, coletada na Estação Experimental de Tratamento de Esgotos da UFES, escuma de uma caixa de gordura do restaurante universitário da UFES e escuma de uma caixa de gordura residencial, pertencente a um condomínio de apartamentos localizado na cidade de Vila Velha, Espírito Santo.

Para o enriquecimento microbiano do solo e dos resíduos oleosos, uma alíquota de $10 \mathrm{~g}$ da amostra foi transferida para frasco Erlenmeyer de $250 \mathrm{~mL}$, contendo $50 \mathrm{~mL}$ de meio mínimo acrescido de $10 \%$ de óleo comestível de soja (Cargill Brazil's Produtos e Serviços). O frasco foi incubado em agitador rotativo a $30^{\circ} \mathrm{C}, 120 \mathrm{rpm}$, por $96 \mathrm{~h}$. Para o isolamento dos fungos foi retirado $1 \mathrm{~g}$ de cada amostra enriquecida, ao qual foram adicionados $100 \mathrm{~mL}$ de água destilada esterilizada, em frasco Erlenmeyer de $250 \mathrm{~mL}$, sendo esse agitado manualmente por $1 \mathrm{~min}$ e deixado em repouso por $5 \mathrm{~min}$. Do sobrenadante foi coletada uma alíquota de $0,1 \mathrm{~mL}$ e a mesma transferida para a superfície de uma placa de Petri contendo $20 \mathrm{~mL}$ do meio de cultura BDA. A partir daí procedeu-se conforme descrito para o isolamento de fungos a partir de tecidos necrosados de plantas e de insetos.

A partir dos cem isolados fúngicos obtidos nas etapas anteriores, foi efetuada uma pré-seleção quanto às atividades lipolíticas extracelular e intracelular. Nessa etapa foram utilizados o meio de cultura sólido - meio basal ou básico $(\mathrm{MB})$ - , indicador de atividade lipásica extracelular, conforme Menezes e Assis (2004), e o meio de cultura sólido - meio mínimo + óleo de soja + rodamina $\mathrm{B}\left(\mathrm{MMOS}_{\mathrm{R}}\right)$-, indicador de atividade lipásica intracelular, ambas em fungos filamentosos.

O meio MB foi assim constituído (g. $\left.\mathrm{L}^{-1}\right)$ : peptona, 10,$0 ; \mathrm{NaCl}, 5,0$; $\mathrm{CaCl}_{2}, 0,1$; ágar, 15,0; pH 6,0 com ( $\mathrm{NaOH} \mathrm{0,1} \mathrm{M).} \mathrm{Como} \mathrm{substrato} \mathrm{lipí-}$ dico foi utilizado $1 \%$ de Tween 80 (sorbitol monolaurato) e ao meio de cultura, após autoclavado e resfriado a $45^{\circ} \mathrm{C}$, foram acrescentados $50 \mathrm{mg}$ de sulfato de estreptomicina e $50 \mathrm{mg}$ de cloranfenicol. Nesse meio, a atividade lipásica extracelular foi detectada pela formação de um halo opaco em torno das colônias fúngicas, por degradação dos sais de lipídio, conforme Hankin e Anagnostakis (1975).

$\mathrm{OMMOS}_{\mathrm{R}}$ foi assim constituído (g.L-1 $)$ : $\left(\mathrm{NH}_{4}\right)_{2} \mathrm{SO}_{4}, 5,0 ; \mathrm{KH}_{2} \mathrm{PO}_{4}, 0,9$; $\mathrm{NaCl}, 1,0 ; \mathrm{MgSO}_{4} .7 \mathrm{H}_{2} \mathrm{O}, 0,3 ; \mathrm{Na}_{2} \mathrm{HPO}_{4}, 6,2$; solução de micronutrientes, $1 \mathrm{~mL}$; ágar, 15. O pH inicial foi de 6,8 (tampão fosfato-salino $0,1 \mathrm{M}$ ).
A solução de micronutrientes apresentou a seguinte composição (mg. $\left.\mathrm{L}^{-1}\right): \mathrm{FeCl}_{3} \cdot 6 \mathrm{H}_{2} \mathrm{O}, 2000 ; \mathrm{ZnCl}_{2}, 50 ; \mathrm{CuCl}_{2} \cdot 2 \mathrm{H}_{2} \mathrm{O}, 30 ; \mathrm{MnCl}_{2} \cdot 2 \mathrm{H}_{2} \mathrm{O}$, 500; $\left(\mathrm{NH}_{4}\right)_{6} \mathrm{Mo}_{7} \mathrm{O}_{24} .4 \mathrm{H}_{2} \mathrm{O}, 50 ; \mathrm{AlCl}_{3}, 50 ; \mathrm{CoCl}_{3} \cdot 6 \mathrm{H}_{2} \mathrm{O}, 2000 ; \mathrm{HCl}$, $1 \mathrm{~mL}$. Foram acrescentados os antibióticos conforme no meio $\mathrm{MB}$, o corante rodamina B (indicador de atividade lipásica) na concentração de 10 mg.L.-1 e 10\% (v/v) de óleo comestível de soja emulsionado com $0,1 \%$ de Tween 80 e $1 \mathrm{~mL}$ de água esterilizada, sob agitação em vortex durante $5 \mathrm{~min}$. Nesse meio, a atividade lipásica intracelular foi detectada pela coloração "laranja fluorescente" exibida pelas colônias fúngicas, quando submetidas à radiação UV com comprimento de onda de $354 \mathrm{~nm}$.

No preparo, $20 \mathrm{~mL}$ dos meios de cultura foram vertidos em placas de Petri (100 mm de diâmetro). Após a solidificação do meio, cada placa foi inoculada com fungo no seu ponto central, sendo três placas para cada isolado fúngico avaliado. Decorrido o período de incubação de $96 \mathrm{~h}$ a $28^{\circ} \mathrm{C}$, foram efetuadas a avaliação do crescimento, cuja medição das colônias foi efetuada com paquímetro, e a avaliação da ocorrência ou não de atividades lipásicas extracelular e ou intracelular, efetuada através de observação das colônias a olho nú.

Para a identificação dos isolados que mostraram reação positiva quanto às atividades lipásicas extra e intracelular, foram preparadas microculturas em lâminas microscópicas de acordo com Menezes e Assis (2004). Foram analisadas, a olho nu e com utilização de microscópio biológico, as características morfológicas macroscópicas e microscópicas apresentadas pelos fungos, após $96 \mathrm{~h}$ de crescimento a $28^{\circ} \mathrm{C}$, que foram comparadas com as chaves classificatórias, descrições e figuras publicadas por Barnet e Hunter (1998), Watanabe (2002) e Webster e Weber (2007).

\section{Seleção de fungos produtores de lipases através do índice enzimático}

Nessa etapa, objetivando a seleção de fungos baseada na quantificação exclusiva da atividade lipásica extracelular, foi calculado o índice enzimático (IE), de acordo com Hankin e Anagnostakis (1975), utilizando a Equação 1.

$\mathrm{IE}=[($ diâmetro da colônia + halo $) /$ diâmetro da colônia $)-1] \times 10$ (1)

Foram avaliados somente os isolados de fungos que exibiram atividade lipásica extracelular na etapa de pré-seleção.

No preparo dos ensaios foi utilizado o meio de cultura MB, preparado conforme descrito anteriormente. Foi utilizada triplicata de cada isolado por placa de Petri, inoculada com três discos de cultura do fungo ( $5 \mathrm{~mm}$ de diâmetro), distribuídos de forma triangular e distanciados cerca de $2 \mathrm{~cm}$ do bordo da placa. Procedeu-se conforme a etapa anterior também quanto à medição das colônias e ao período de incubação. 


\section{Avaliação do potencial hidrolítico de Penicillium sp. F002 e Rhizomucor sp. F018}

Nessa etapa foi avaliado, de forma indireta, o potencial hidrolítico dos isolados Penicillium sp. F002 e Rhizomucor sp. F018, sobre óleo comestível de soja (OS) e escuma de caixa de gordura do restaurante universitário da UFES (ECGRU). O processo de fermentação adotado foi em estado sólido, com utilização de respirômetro alternativo ao de Bartha, conforme Teles, Munaro e Cassini (2009). Foram quantificadas as variáveis produção acumulada de $\mathrm{CO}_{2}$, remoção de óleos e graxas e crescimento de biomassa dos fungos.

Os isolados Penicillium sp. F002 e Rhizomucor sp. F018 foram escolhidos em função dos melhores resultados obtidos nas etapas anteriores, de pré-seleção e seleção, quanto à atividade lipásica extracelular e intracelular, respectivamente (Figuras 1D e 2). Para a obtenção do inóculo a ser utilizado, os fungos foram propagados a $28^{\circ} \mathrm{C}$ por 5 dias em placas de Petri com o meio de cultura BDA. Os esporos foram removidos por adição de $5 \mathrm{~mL}$ de água destilada esterilizada sobre a colônia, seguida de raspagem com alça de Drigalski. A contagem foi em câmara de Neubauer, e a concentração final do inóculo foi de $10^{7}$ esporos. $\mathrm{mL}^{-1}$.

Como padrão para atividade enzimática foi utilizada uma lipase comercial (lipase recombinante de Rhizomucor mihei sobre Aspergillus oryzae, $20 \mathrm{U} \cdot \mathrm{mL}^{-1}$ ) na concentração de $10 \mu \mathrm{L} \cdot \mathrm{mL}^{-1}$.

Foi utilizada uma mistura com $50 \%$ de areia e $50 \%$ de vermiculita (v/v) como material estruturante, com o objetivo de simular condições naturais de solos. A areia grossa (0,6 a $2 \mathrm{~mm}$ de diâmetro) foi previamente lavada com uma solução de $\mathrm{HCl} 0,1 \mathrm{M}$ e repetidas vezes com água corrente, seguindo-se sua secagem em estufa a $100^{\circ} \mathrm{C}$ por $24 \mathrm{~h}$ e autoclavagem a $120^{\circ} \mathrm{C}$ por $30 \mathrm{~min}$. Procedeu-se da mesma forma em relação à vermiculita, com exceção da lavagem com o ácido.

Previamente à montagem do sistema respirométrico, o OS e a escuma de caixa de gordura foram analisados quanto ao teor de sólidos voláteis (SV), demanda química de oxigênio (DQO), teor de óleos e graxas $(\mathrm{O} \& \mathrm{G})$ e $\mathrm{pH}$, de acordo com o Standard Methods for the Examination of Water and Wastewater (APHA, 2005). Os valores obtidos para os citados parâmetros encontram-se expressos na Tabela 1.

Tabela 1 - Valores obtidos para os parâmetros físico-químicos do óleo de soja comercial e da escuma de caixa de gordura do restaurante universitário da Universidade Federal do Espírito Santo.

\begin{tabular}{|c|c|c|}
\hline Parâmetro & $\begin{array}{l}\text { Óleo de soja } \\
\text { comercial }\end{array}$ & $\begin{array}{l}\text { Escuma de caixa } \\
\text { de gordura }\end{array}$ \\
\hline Sólidos voláteis (mg.L-1) & 922110,45 & 756472,75 \\
\hline Demanda química de oxigênio (mg. $\mathrm{L}^{-1}$ ) & 1429001,83 & 922991,29 \\
\hline Teor de óleos e graxas (mg.L'1) & 921936,67 & 595478,25 \\
\hline $\mathrm{pH}$ & 6,08 & 5,60 \\
\hline
\end{tabular}

Antes da inserção dos substratos oleosos no material estruturante, padronizou-se o seu teor de óleos e graxas para o valor aproximado de 60 g. $\mathrm{L}^{-1}$.

As repetições constituíram-se de frascos de acrílico $(900 \mathrm{~mL})$, cilíndricos e herméticos por vedação por pressão e borracha, utilizados em triplicata para cada tratamento experimental. Cada frasco (reator) conteve $100 \mathrm{~g}$ do material estruturante ao qual foi adicionado o meio mineral mínimo (MM), até $50 \%$ de sua capacidade de campo, $10 \mathrm{~g}$ do óleo de soja ou da escuma de caixa de gordura, $1 \mathrm{~mL}$ do inoculante e/ou da lipase comercial, conforme o tratamento experimental, exceto para o controle. Após as adições, procedeu-se a mistura dos conteúdos de cada frasco, seguindo-se a introdução de um frasco de polietileno de $50 \mathrm{~mL}$, que recebeu $20 \mathrm{~mL}$ de solução de $\mathrm{NaOH}$ 0,5 mol.L-1 , destinada à absorção do $\mathrm{CO}_{2}$ da atividade de biodegradação, substituída diariamente por outra livre de íons carbonato no transcorrer do experimento. De cada frasco foram retiradas 3 amostras de $1 \mathrm{~g}$ do substrato: 2 para a quantificação da biomassa fúngica e a 1 para o teor de óleos e graxas, aos 10 20 e 30 dias experimentais.

A quantificação do $\mathrm{CO}_{2}$ foi realizada a cada 24 horas durante 30 dias, por meio de leitura de condutividade elétrica. No processo de biodegradação ocorre o decaimento da condutividade elétrica na solução de $\mathrm{NaOH}$ na medida da reação com o $\mathrm{CO}_{2}$ liberado, formando inicialmente o $\mathrm{H}_{2} \mathrm{CO}_{3}$, que em seguida dá origem ao $\mathrm{NaHCO}_{3}$ e ao $\mathrm{Na}_{2} \mathrm{CO}_{3}$ (TELES; MUNARO, CASSINI, 2009). Foi utilizada a Equação 2.

$\mathrm{Co}_{2}(\mathrm{mg})=\mathrm{V} \times \mathrm{M} \times 22 \frac{\left(\mathrm{C}_{1}-\mathrm{C}_{\mathrm{X}}\right)}{\left(\mathrm{C}_{1}-\mathrm{C}_{2}\right)}$

onde: $\mathrm{V}$ = volume da solução de $\mathrm{NaOH}(\mathrm{mL})$ empregada na absorção do $\mathrm{CO}_{2} ; \mathrm{M}=$ concentração da solução de $\mathrm{NaOH}(\mathrm{mL})$ empregada na absorção do $\mathrm{CO}_{2}\left(\right.$ mol.L $\left.^{-1}\right) ; \mathrm{C}_{1}=$ medida da condutividade elétrica da solução padrão de $\mathrm{NaOH}\left(\mathrm{mS} \mathrm{cm}^{-1}\right) ; \mathrm{C}_{\mathrm{x}}=$ medida da condutividade elétrica da amostra; $\mathrm{C}_{2}=$ medida da condutividade elétrica da solução padrão de $\mathrm{Na}_{2} \mathrm{CO}_{3}$.

O teor de óleos e graxas foi quantificado conforme o método de extração contínua em aparelho tipo Soxhlet, segundo o Standard Methods for the Examination of Water and Wastewater (APHA, 2005), baseado na quantificação gravimétrica do material extraído com solvente orgânico (hexano). As amostras analisadas foram de $1 \mathrm{~g}$, coletadas aos 0 (data da instalação do experimento), 10, 20 e 30 dias, ocasiões em que foram acidificadas com $\mathrm{HCl}$ para $\mathrm{pH}$ 2,0 e armazenadas em freezer a $-25^{\circ} \mathrm{C}$, até serem utilizadas nas análises.

A biomassa fúngica foi quantificada indiretamente através da determinação do teor de ergosterol detectado nos substratos de fermentação, através do método de cromatografia líquida de alta eficiência (CLAE), conforme Montgomery et al. (2000), com modificações. Para a extração do ergosterol das amostras foi utilizado $1 \mathrm{~g}$ do substrato em um tubo de 
ensaio, ao qual adicionou-se $5 \mathrm{~mL}$ de metanol e procedeu-se a agitação em vortex, durante $1 \mathrm{~min}$. Após repouso de $10 \mathrm{~min}$, os sobrenadantes foram transferidos para tubos tipo Eppendorf de 1,5 mL e centrifugados por $10 \mathrm{~min}$ a $10.000 \mathrm{rpm}$ e $22^{\circ} \mathrm{C}$. Os sobrenadantes foram então filtrados em papel de filtro com porosidade de $0,22 \mu \mathrm{m}$ e armazenados em frascos tipo vials, que foram mantidos em freezer a $-25^{\circ} \mathrm{C}$ até a sua utilização, que ocorreu no máximo em 30 dias.

Para as análises foi utilizado cromatógrafo (Shimadzu, modelo LC $20 \mathrm{AD} / \mathrm{T}$ ) com sistema binário de solventes, equipado com coluna $\mathrm{C} 18$ (100 por 2,1 mm). A fase móvel foi isocrática com metanol (grau CLAE) e água (qualidade Milli-Q) na razão 95:5 (v/v), filtrados e degaseificados por $15 \mathrm{~min}$, com a vazão de $0,5 \mathrm{~mL} \cdot \mathrm{min}^{-1}$. O tempo de corrida durou aproximadamente 7 min e a identificação, bem como integração do pico de ergosterol, foi por comparação de tempos de retenção do padrão e da amostra; e a pureza verificada através dos espectros de absorbância obtidos no início, ápice e término do pico, cuja leitura ocorreu a $282 \mathrm{~nm}$. Para a construção da curva padrão (padronização externa), que foi linear, passou pela origem e cobriu a faixa de concentração das amostras, utilizou-se ergosterol com pureza mínima de 95\% e 7 pontos de leitura, cujas concentrações variaram de 5,0 a 500 ug. $\mathrm{mL}^{-1}$.

Para aferir o conteúdo de ergosterol presente na biomassa pura de Penicillium sp. F002 e Rhizomucor sp. F018, os fungos foram cultivados em frascos Erlenmeyers de $250 \mathrm{~mL}$ com MMOS por 30 dias, em shaker a $30^{\circ} \mathrm{C}$ e $150 \mathrm{rpm}$. Aos 10, 20 e 30 dias foram coletadas suas biomassas através de filtragem, seguindo-se sua lavagem com acetona e sucessivas lavagens em água com qualidade milli-Q. Transferidas para papéis de filtro previamente secos a $60^{\circ} \mathrm{C}$, e pesados, procedeu-se a sua secagem a essa temperatura até peso constante e então a pesagem.

A biomassa seca foi obtida pela diferença entre as pesagens dos papéis, sem e com a presença das biomassas. Amostras de $1 \mathrm{~g}$ de biomassa seca foram congeladas com a utilização de nitrogênio líquido e trituradas em almofariz, que em seguida foram acrescidos de $5 \mathrm{~mL}$ de metanol. Em seguida procedeu-se conforme descrito para as análises cromatográficas.

\section{Análises estatísticas}

Para as análises estatísticas dos dados obtidos e a confecção dos gráficos e tabelas, foram utilizados os softwares SPSS for Windows versão 11.5.0 e Excel (Microsoft Office Home and Student 2013).

\section{RESULTADOS E DISCUSSÃO}

\section{Isolamento, pré-seleção e identificação de fungos filamentosos produtores de lipases}

A partir das amostras dos tecidos vegetais e dos insetos necrosados por fungos, como também do solo e das escumas de esgoto sanitário e de caixas de gordura, foram obtidos cem isolados de fungos filamentosos, dos quais 67 apresentaram crescimento variável e reação positiva quanto às atividades lipásicas extracelular e ou intracelular, nos meios de cultura $\mathrm{MB}$ e MMOS $_{R}$, respectivamente. Os isolados que apresentaram reação positiva foram identificados ao nível de gênero e enquadrados como pertencentes a Aspergillus, Beauveria, Botrytis, Cladosporium, Colletotrichum, Fusarium, Geotrichum, Mucor, Penicillium, Rhizomucor e Verticillium (Tabela 2).

A atividade lipásica é comumente medida pelo monitoramento da liberação de ácidos graxos ou glicerol a partir do triacil glicerol; e o uso de meio sólido com substratos indutores como óleos vegetais, triglicerídeos padrões (tributirina, trioleína), Tween 80 e corantes tem sido fartamente descrito na literatura, visando a pré-seleção de microrganismos produtores de lipases (SANDOVAL \& MARTY, 2007). Para atender a esse propósito, no presente trabalho, os meios de cultura e procedimentos adotados foram considerados satisfatórios com base nos resultados obtidos, visto que os meios de cultura sólidos $\mathrm{MB}$ e $\mathrm{MMOS}_{\mathrm{R}}$ permitiram, partindo-se de um grande número de isolados, evitar escapes no processo de pré-seleção, advindos da forma predominante e detectável de atividade lipásica exibida pelos fungos isolados.

No meio de cultura MB, ocorreu a formação de um halo opaco em torno das colônias fúngicas (Figuras $1 \mathrm{~B}$ e C) de 4 lisolados fúngicos dentre os 100 analisados. Tal reação decorre da atividade lipásica extracelular, com a formação de cristais de cálcio do ácido láurico, pela completa degradação dos sais de lipídio (HANKIN \& ANAGNOSTAKIS, 1975; COLEN; JUNQUEIRA; MORAES-SANTOS, 2006).

No meio de cultura $\mathrm{MMOS}_{\mathrm{R}}$, observou-se a coloração "laranja fluorescente" em toda a extensão das colônias fúngicas (Figura 1D), quando submetidas à radiação UV com comprimento de onda de $354 \mathrm{~nm}$, de 51 isolados dentre os 100 analisados. Essa reação decorre da atividade lipolítica intracelular, pela presença de cadeias longas de glicerídios não solúveis pela hidrólise enzimática no interior das hifas (KIM et al., 2001 apud HASAN; SHAH; HAMEED, 2009).

Apesar da utilidade de meios-ágar para a detecção de atividade lipásica de fungos filamentosos, é necessário que se leve em conta variações de resultados, de acordo não somente com o isolado, mas também com a composição do meio de cultura utilizado e as condições de cultivo, como as fontes de carbono e nitrogênio, o pH e a temperatura. Dificuldades podem advir também do rápido crescimento das colônias em certas espécies, da baixa atividade lipolítica em outras e da possibilidade de reações de corantes com metabólitos não enzimáticos, levando à expressão de falsos resultados (COLEN; JUNQUEIRA; MORAESSANTOS, 2006; SINGH \& MUKHOPADHYAY, 2012).

\section{Seleção de fungos produtores de lipases através do índice enzimático}

Nessa etapa, foi utilizada a razão entre o raio do halo opaco e o raio das colônias dos fungos, medida com paquímetro e denominada IE para quantificar a atividade lipásica extracelular de 41 isolados fúngicos 
Tabela 2 - Gênero e características dos isolados fúngicos obtidos, quanto à procedência, crescimento de colônias e atividade lipásica, nos meios MB e MMOS $_{R^{\prime}}$

\begin{tabular}{|c|c|c|c|c|c|c|}
\hline \multirow{2}{*}{ Gênero } & \multirow{2}{*}{ Isolado } & \multirow{2}{*}{ Procedência } & \multicolumn{2}{|c|}{ Colônia $(\mathrm{mm})^{*}$} & \multirow{2}{*}{$\begin{array}{c}\text { Reação } \\
\text { MB }\end{array}$} & \multirow{2}{*}{$\begin{array}{l}\text { Reação } \\
\text { MMOS }\end{array}$} \\
\hline & & & $\mathrm{MB}$ & $\mathrm{MMOS}_{\mathrm{R}}$ & & \\
\hline \multirow{5}{*}{ Aspergillus } & F092 & Caixa de gordura RU & 26,0 & $* *$ & + & - \\
\hline & FO31 & Escuma de caixa de gordura RU & 22,0 & ** & + & - \\
\hline & F068 & Escuma de caixa de gordura RU & 31,0 & 32,3 & - & + \\
\hline & FO79 & Escuma de caixa de gordura RU & 31,3 & $* *$ & + & - \\
\hline & F081 & Escuma de caixa de gordura RU & 35,3 & 44,0 & + & + \\
\hline \multirow{26}{*}{ Beauveria } & F009 & Atta capiguara (adulto) & 14,8 & 4,5 & + & + \\
\hline & FO35 & Spodoptera frugiperda (larva) & 30,2 & 6,5 & + & + \\
\hline & FO36 & Hypothenemus hampei (adulto) & 18,3 & 7,8 & + & + \\
\hline & FO37 & Hypothenemus hampei (adulto) & 18,3 & 7,8 & + & + \\
\hline & FO38 & Hypothenemus hampei (adulto) & 13,7 & 5,0 & + & + \\
\hline & FO39 & Hypothenemus hampei (adulto) & 16,7 & 6,7 & + & + \\
\hline & $\mathrm{FO} 40$ & Hypothenemus hampei (adulto) & 18,7 & 9,3 & + & + \\
\hline & FO41 & Hypothenemus hampei (adulto) & 13,8 & 5,8 & + & + \\
\hline & FO42 & Hypothenemus hampei (adulto) & 14,8 & 7,3 & + & + \\
\hline & FO43 & Hypothenemus hampei (adulto) & 15,5 & 5,8 & + & + \\
\hline & FO44 & Hypothenemus hampei (adulto) & 13,0 & 5,2 & + & + \\
\hline & FO45 & Hypothenemus hampei (adulto) & 9,3 & 3,8 & + & + \\
\hline & FO46 & Hypothenemus hampei (adulto) & 14,7 & 5,8 & + & + \\
\hline & FO47 & Hypothenemus hampei (adulto) & 14,3 & 5,8 & + & + \\
\hline & FO48 & Hypothenemus hampei (adulto) & 12,2 & 4,8 & + & + \\
\hline & FO49 & Hypothenemus hampei (adulto) & 14,7 & 5,5 & + & + \\
\hline & FO5O & Hypothenemus hampei (adulto) & 14,5 & 5,8 & + & + \\
\hline & F052 & Hypothenemus hampei (adulto) & 16,3 & 7,5 & + & + \\
\hline & FO53 & Hypothenemus hampei (adulto) & 15,8 & 7,2 & + & + \\
\hline & FO54 & Hypothenemus hampei (adulto) & 12,5 & 5,5 & - & + \\
\hline & FO55 & Hypothenemus hampei (adulto) & 16,2 & 5,3 & - & + \\
\hline & F056 & Hypothenemus hampei (adulto) & 16,7 & 6,7 & - & + \\
\hline & F059 & Hypothenemus hampei (adulto) & 16,5 & 7,0 & - & + \\
\hline & F060 & Deois flavopicta (adulto) & 17,8 & 8,7 & - & + \\
\hline & F061 & Mahanarva posticata (adulto) & 18,0 & 7,8 & - & + \\
\hline & F092 & Hypothenemus hampei (adulto) & 14,8 & 5,5 & - & + \\
\hline Botrytis & F093 & Escuma de caixa de gordura $\mathrm{R}$ & 39,5 & 14,0 & - & + \\
\hline \multirow{4}{*}{ Cladosporium } & FO27 & Musa acuminata (fruto) & 10,7 & ** & + & - \\
\hline & FO28 & Musa acuminata (fruto) & 9,7 & $* *$ & + & - \\
\hline & FO72 & Carica papaya (fruto) & 11,3 & 6,7 & + & + \\
\hline & F098 & Carica papaya (fruto) & 10,7 & 6,0 & + & + \\
\hline \multirow{6}{*}{ Colletotrichum } & F064 & Carica papaya (fruto) & 20,7 & $\star *$ & + & - \\
\hline & F065 & Carica papaya (fruto) & 24,5 & 10,7 & + & + \\
\hline & F066 & Carica papaya (fruto) & 31,7 & $\star *$ & + & - \\
\hline & FO71 & Carica papaya (fruto) & 28,7 & $* *$ & + & - \\
\hline & FO26 & Musa acuminata (fruto) & 38,7 & ** & + & - \\
\hline & FO76 & Licania tomentosa (folha) & 30,2 & 13,2 & + & + \\
\hline \multirow{6}{*}{ Fusarium } & F010 & Musa acuminata (caule) & 44,7 & 18,8 & - & + \\
\hline & F067 & Carica papaya (fruto) & 40,3 & 36,8 & - & + \\
\hline & FO74 & Carica papaya (fruto) & 35,0 & 42,2 & - & + \\
\hline & FO75 & Carica papaya (fruto) & 50,0 & $* *$ & + & - \\
\hline & F084 & Solo de pomar & 16,7 & 7,3 & - & + \\
\hline & FO90 & Escuma de caixa de gordura $\mathrm{R}$ & 45,0 & 27,0 & - & + \\
\hline \multirow{3}{*}{ Geotrichum } & F096 & Escuma de caixa de gordura RU & 31,8 & 19,5 & + & + \\
\hline & F097 & Escuma de caixa de gordura RU & 27,3 & 16,3 & - & + \\
\hline & F099 & Escuma de caixa de gordura RU & 25,2 & 13,8 & - & + \\
\hline
\end{tabular}


Tabela 2 - Continuação.

\begin{tabular}{|c|c|c|c|c|c|c|}
\hline \multirow{2}{*}{ Gênero } & \multirow{2}{*}{ Isolado } & \multirow{2}{*}{ Procedência } & \multicolumn{2}{|c|}{ Colônia $(\mathrm{mm})^{*}$} & \multirow{2}{*}{$\begin{array}{c}\text { Reação } \\
\text { MB }\end{array}$} & \multirow{2}{*}{$\begin{array}{l}\text { Reação } \\
\text { MMOS }_{\text {F }}\end{array}$} \\
\hline & & & MB & MMOS $_{R}$ & & \\
\hline \multirow{10}{*}{ Penicillium } & FOO2 & Escuma de caixa de gordura RU & 9,7 & $\star \star *$ & + & - \\
\hline & F006 & Escuma de caixa de gordura RU & 9,0 & ** & + & - \\
\hline & F015 & Escuma de caixa de gordura RU & 26,2 & 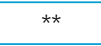 & + & - \\
\hline & $\mathrm{FO} 22$ & Escuma de caixa de gordura RU & 21,7 & $* *$ & + & - \\
\hline & FO29 & Escuma de caixa de gordura RU & 14,7 & 7,3 & - & + \\
\hline & F062 & Escuma de caixa de gordura RU & 18,7 & 9,3 & - & + \\
\hline & F069 & Escuma de caixa de gordura RU & 13,3 & 7,0 & - & + \\
\hline & F083 & Solo de pomar & 22,7 & 10,5 & - & + \\
\hline & F087 & Escuma de caixa de gordura $\mathrm{R}$ & 32,5 & ** & + & - \\
\hline & F089 & Escuma de caixa de gordura $\mathrm{R}$ & 7,3 & 6,0 & + & + \\
\hline \multirow{5}{*}{ Rhizomucor } & F012 & Escuma de esgoto sanitário & $>90,0$ & 38,7 & - & + \\
\hline & F018 & Escuma de caixa de gordura RU & $>90,0$ & 59,5 & - & + \\
\hline & FO19 & Escuma de caixa de gordura RU & $>90,0$ & 34,3 & - & + \\
\hline & FO93 & Escuma de caixa de gordura R & $>90,0$ & 56,0 & - & + \\
\hline & $\mathrm{F} 100$ & Escuma de caixa de gordura RU & $>90,0$ & 35,7 & - & + \\
\hline Verticillium & FOO7 & Escuma de esgoto sanitário & 8,3 & 3,0 & + & + \\
\hline
\end{tabular}

*Média de 3 repetições e leitura com 96 horas de incubação a $28^{\circ} \mathrm{C}$ e escuro; MB: meio basal; MMOS : meio mínimo + óleo de soja + rodamina B; **inexistência de crescimento e ou biomassa rala e pouco perceptível, dificultando a medição; R: residencial; RU: restaurante universitário da Universidade Federal do Espírito Santo.
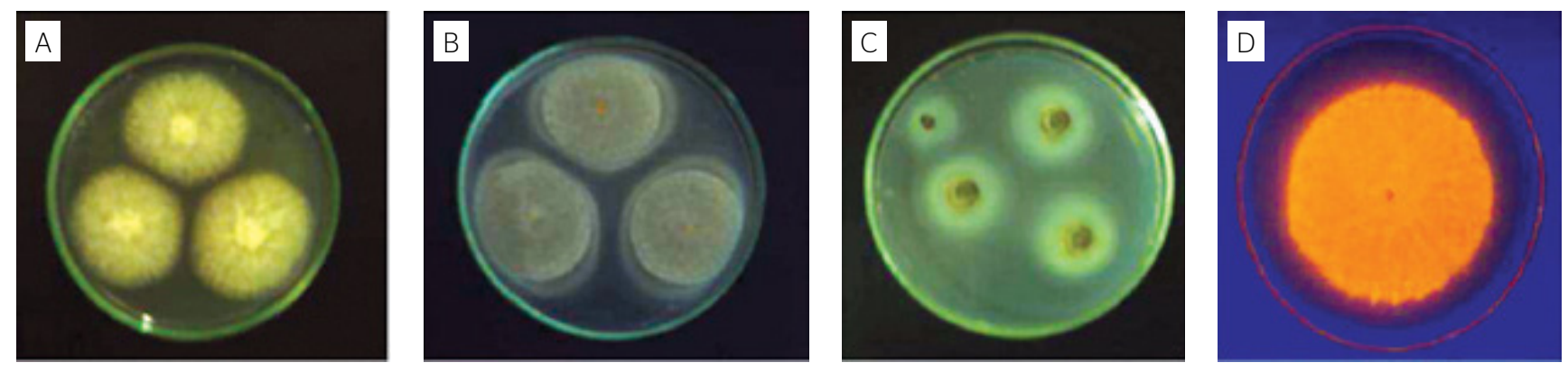

Figura 1 - Ausência de atividade lipásica detectada para Fusarium sp. (F067) no meio MB (A); atividade lipásica (halo opaco) detectada para Colletotrichum gloeosporioides (FO76) e Cladosporium sp. (F028) no meio MB (B, C); atividade lipásica (cor laranja fluorescente) detectada para Rhizomucor sp. (FO18) no meio $\mathrm{MMOS}_{\mathrm{R}}$, sob radiação ultravioleta (D). Incubação a $28^{\circ} \mathrm{C}$, por 96 horas, no escuro.

pré-selecionados (etapa anterior). Os 10 isolados com maiores valores obtidos para essa variável, dentre os 41 analisados, foram os seguintes, conforme ordem decrescente de atividade: F002, F096, F035, F007, F041, F028, F045, F048, F076, F064 e F065 (Figura 2).

Utilizando metodologia semelhante à utilizada neste trabalho, Colen, Junqueira e Moraes-Santos (2006) avaliaram a capacidade de produção de lipase por 73 isolados fúngicos, 14 obtidos de coleções de cultura e 59 obtidos de amostras do solo do cerrado de Minas Gerais, com o emprego de técnicas de enriquecimento seletivo. Foram selecionados 21 isolados em função da razão entre os raios do halo lipolítico e das colônias, 11 deles considerados bons produtores de lipases, sob condições de fermentação em estado líquido (culturas agitadas) e sólido, em etapa posterior.

\section{Potencial hidrolítico de}

\section{Penicillium sp. F002 e Rhizomucor sp. F018}

Nessa etapa foi avaliado o potencial hidrolítico dos isolados fúngicos Penicillium sp. F002 e Rhizomucorsp. F018, anteriormente selecionados por se destacaram na expressão de suas atividades lipásicas extracelular e intracelular, respectivamente. A hidrólise de óleo comestível de soja e de escuma de caixa de gordura foi indiretamente estimada em condições de fermentação em estado sólido, em um sistema respirométrico aeróbio, através das variáveis produção de $\mathrm{CO}_{2}$, percentagem de remoção de óleos e graxas do substrato e crescimento da biomassa fúngica.

Os resultados mostrados nas Figuras 3A e B permitiram verificar que os fungos inoculados levaram à produção de maior quantidade de $\mathrm{CO}_{2}$ indicando maior quantidade de carbono biodegradado. A menor produção de $\mathrm{CO}_{2}$ ocorreu nos controles (tratamentos nos quais não ocorreu inoculação). A remoção do teor de óleos e graxas mostrou-se com tendência inversamente proporcional à produção de $\mathrm{CO}_{2}$, em todos os tratamentos analisados.

Observou-se maior produção acumulada de $\mathrm{CO}_{2}$ nos fermentados com Rhizomucor sp. F018, que tiveram o acréscimo da lipase comercial, tanto para o óleo de soja (OSLF018) quanto para a escuma de caixa de gordura (ECGRULF018). Esse resultado foi atribuído à facilitação 
de atividade lipásica intracelular, cujo potencial já havia sido demonstrado por esse isolado etapa de pré-seleção, decorrente do choque enzimático pela dose elevada da lipase, que acelerou a degradação dos triglicerídeos presentes no substrato.

Nos fermentados com Penicillium sp. F002, o acréscimo de lipase aos tratamentos experimentais (OSLF002 e ECGRULF002) resultou em elevação da produção acumulada de $\mathrm{CO}_{2}$, porém em níveis inferiores. Tal resultado pode ser atribuído ao potencial inferior para atividade lipásica intracelular apresentado por esse isolado, em relação ao Rhizomucor sp. F018, previamente constatado neste trabalho, portanto, à capacidade inferior de resposta ao choque enzimático oriundo do acréscimo da lipase comercial utilizada.

Os valores obtidos para produção acumulada de $\mathrm{CO}_{2}$ e redução do teor de óleos e graxas (Tabela 3), relativos aos tratamentos sem a inoculação dos fungos, porém com o acréscimo de lipase comercial, tanto para o óleo de soja (OSL) quanto para a escuma de caixa de gordura
(ECGRUL), foram atribuídos à ação de fungos e bactérias contaminantes, não quantificados, oriundos do ambiente de trabalho e ou sobreviventes aos processos de esterilização previamente utilizados, beneficiados também pelo choque enzimático nos substratos.

Métodos microbiológicos como contagem de unidades formadoras de colônias são amplamente empregados para estimar a quantidade de biomassa fúngica presente em vários tipos de substratos. Porém, os valores das unidades formadoras não refletem exatamente a biomassa fúngica, mas sim a quantidade de esporos fúngicos produzidos, além de serem trabalhosos e demorados, conforme Gutarowska e Zakowska (2009). Por isso a opção pela utilização do conteúdo de ergosterol para estimar a quantidade de biomassa fúngica de Penicillium sp. F002 e Rhizomucor sp. F018 presente nos substratos de cultivo, analisado por CLAE, adaptando-se a metodologia às condições e objetivos para sua utilização no presente trabalho. Foram também levados em consideração na definição metodológica, os fatos de que o conteúdo de

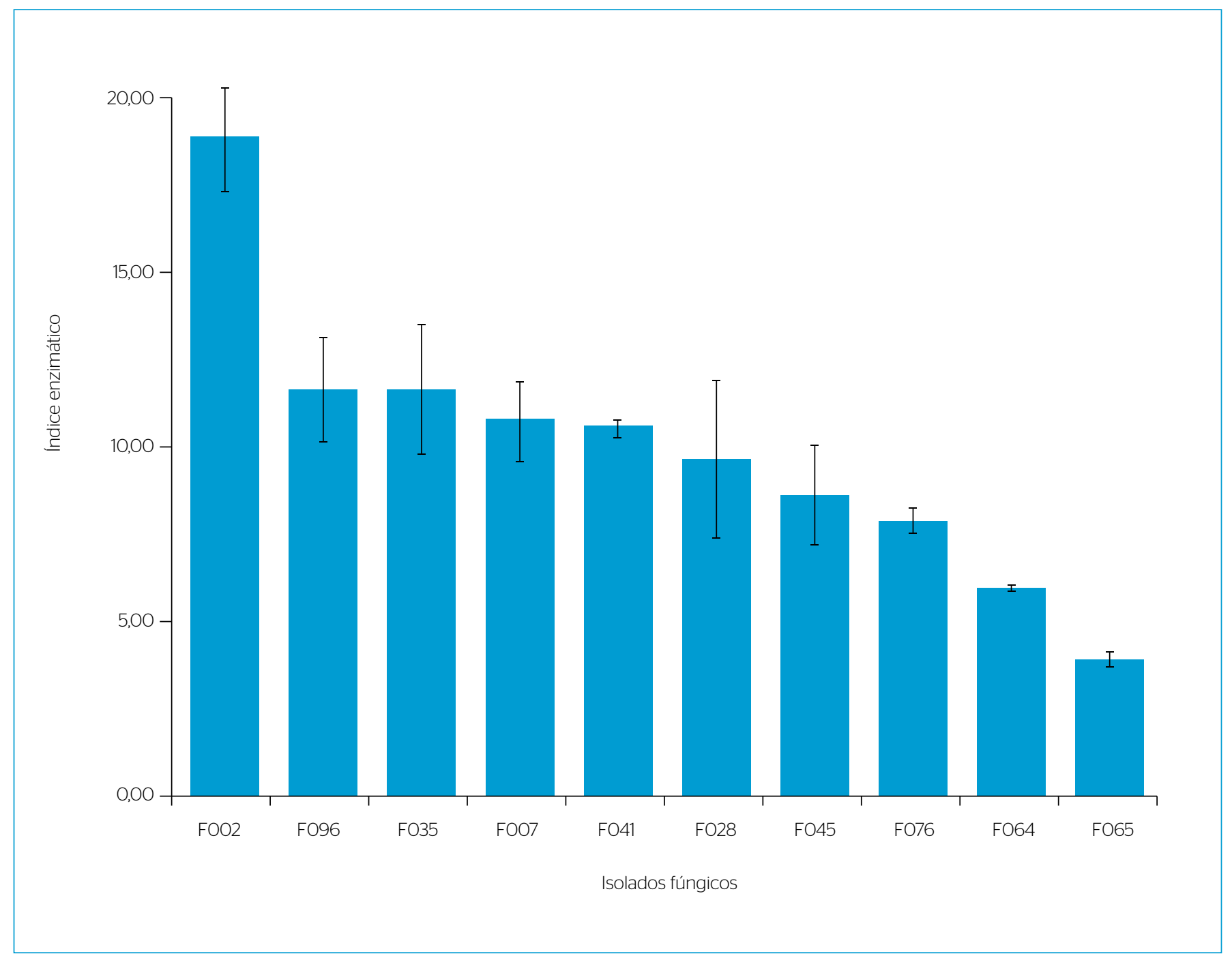

Figura 2 - Dez isolados de fungos filamentosos com os maiores valores de índice enzimático detectados no meio de cultura basal, com $96 \mathrm{~h}$ de incubação a $28^{\circ} \mathrm{C}$. 
ergosterol difere entre gêneros e espécies, e que sua síntese e distribuição é variável com os estágios de crescimento ou idade fisiológica dos fungos (MONTGOMERY et al., 2000).

Para se chegar aos valores de biomassa fúngica expressos na Tabela 3, foi utilizada a razão de conversão ergosterol - biomassa fúngica, definida como micrograma de ergosterol por grama de biomassa fúngica seca $\left(\mu \cdot \mathrm{g}^{-1}\right)$, que apresentou os valores médios $(\mathrm{n}=3)$ de 1,28 (10 dias), 1,57 (20 dias) e 1,49 (30 dias) para Penicillium sp F002 e de 1,55 (10 dias), 1,52 (20 dias) e 1,54 (30 dias) para Rhizomucor sp F018. O crescimento de biomassa desses fungos, analisada nos três tempos, foi quantificado com base nos valores da razão de conversão para eles definidas e nos valores quantificados de ergosterol, através de CLAE, a partir de amostras do substrato dos diferentes tratamentos, e os resultados expressos em miligrama de biomassa fúngica por grama de substrato seco (mg.g $\left.{ }^{-1}\right)$. Não foram determinados os valores de biomassa fúngica para os tratamentos que não foram inoculados com os fungos.

Conforme a Tabela 3, maior produção de $\mathrm{CO}_{2}$ e crescimento da biomassa e, menor teor de óleos e graxas (maior remoção), foram verificados em relação aos tratamentos com inoculação de Penicillium
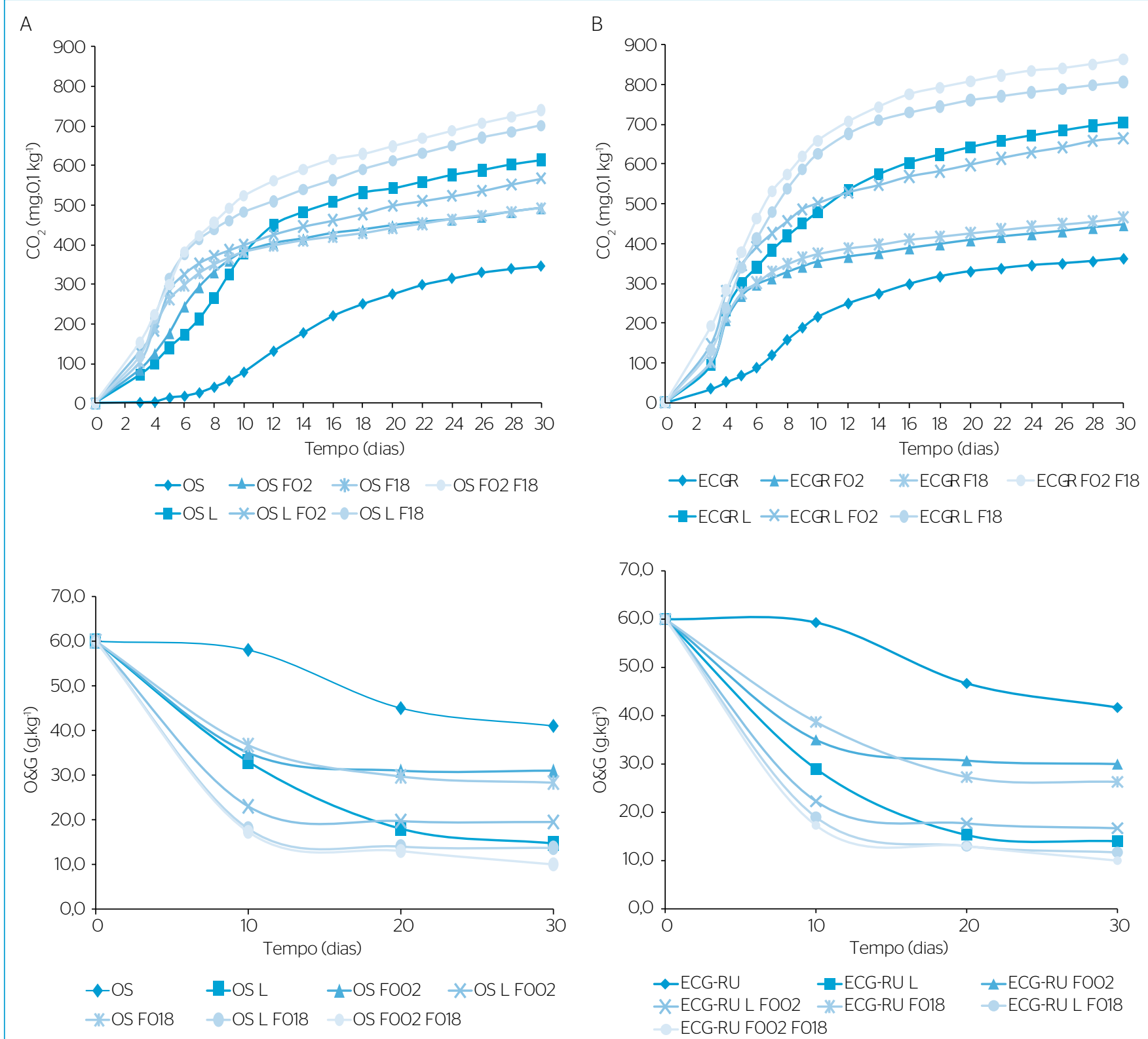

O\&G: teor de óleos e graxas; OS: óleo de soja; L: lipase comercial; FOO2: fungo Penicillium sp.; FO18: fungo Rhizomucor sp: ECG-RU: escuma de caixa de gordura do

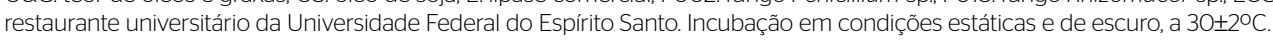

Figura 3 - Produção acumulada de $\mathrm{CO}_{2}$ (30 dias) e teor de óleos e graxas aos 0, 10, 20 e 30 dias, a partir da biodegradação aeróbia de óleo de soja comercial (A) e escuma de caixa de gordura (B). 
sp. F002 e Rhizomucor sp. F018. As diferenças estatisticamente significativas entre os valores das médias foram definidas através da utilização do teste de Tukey $(\mathrm{p}=0,05)$. Foram observadas correlações lineares (Pearson) positivas e fortes entre as variáveis produção de $\mathrm{CO}_{2}$ e crescimento da biomassa fúngica, e negativas e fortes entre produção de $\mathrm{CO}_{2}$ ou crescimento da biomassa e teores de óleos e graxas presentes no substrato, nas quantificações efetuadas aos 10 , 20 e 30 dias do experimento, em relação aos tratamentos com inoculação, com valores para $\mathrm{R}^{2}$, nas análises de regressão linear, que variaram de 0,81 a 0,99 .

Os valores obtidos para as três variáveis analisadas, relativos aos tratamentos em que Penicillium sp. F002 e Rhizomucor sp. F018 foram inoculados em conjunto (inóculo misto), superiores estatisticamente, podem ser atribuídos ao efeito de complementaridade dos seus potenciais de atividade lipásica, que superou até mesmo o efeito do acréscimo da lipase comercial, nos tratamentos nos quais foram inoculados isoladamente ou não foram inoculados e/ou à concentração inicial de esporos (duplicada) recebida pelos tratamentos com a inoculação mista, resguardados possíveis efeitos de adição, sinérgicos e ou antagônicos que podem ocorrer advindos da interação entre os isolados inoculados, conforme Webster e Weber (2007).

Muitas espécies de Penicillium tem se mostrado boas produtoras de lipases extracelulares, tais como $P$. citrinum, $P$. cyclopium, P. simplicissimum, P. caseicolum, P. restrictum, P. expansum, P. corylophilum, P. chrysogenum, $P$. roqueforti, $P$. camembertii, P. crustosum, P. abeanum, dentre outras (SINGH \& MUKHOPADHYAY, 2012; TURKI, 2013), corroborando os resultados obtidos neste trabalho. O mesmo verifica-se em relação ao Rhizomucor, cuja espécie em destaque é $R$. mihei, pela produção da lipase de Rhizomucor mihei (LRM), uma das enzimas mais comercializadas em todo o mundo, sobre a qual Rodrigues \& Fernandez-Lafuente (2010) publicaram extensa revisão acerca dos principais usos, características e alguns dos aspectos mais relevantes na transformação de óleos e gorduras.

No presente trabalho, no entanto, o isolado Rhizomucor sp. F018, destacou-se pelo potencial exibido principalmente para atividade lipásica intracelular, a exemplo de espécies com posicionamento taxonômico muito próximo, como Mucor circineloides, que vem demonstrando grande potencial para utilização como biocatalisador lipásico de célula integral, conforme relatos de Andrade et al. (2014) e Carvalho et al. (2015).

Quando se pretende selecionar fungos produtores de lipases, como no presente trabalho, os resultados quanto à forma de expressão da atividade lipásica (extracelular ou intracelular) devem ser considerados com muito critério, visto que muita variação tem sido relatada, tanto para cultivos submersos quanto para cultivos em substratos sólidos, em função dos fatores já anteriormente citados. Como exemplo, com o objetivo de selecionar fungos para utilização na forma de células integrais lipásicas, na transesterificação etanólica de óleo de babaçu, Andrade et al. (2012) verificaram que os isolados Rhizopus oryzae (URM 3231 e 4692), Mucor circinelloides (URM 4140 e 4182) e Penicillium citrinum (URM 4216) mostraram-se bons produtores de lipase intracelular, enquanto Mucor hiemalis (URM 4144) e Mucor piriformis (URM 4145) foram fracos produtores, quando cultivados em substrato sólido.

Normalmente as enzimas de uso industrial são produzidas na presença de indutores. No caso de lipases, a presença no substrato

Tabela 3 - Produção acumulada de $\mathrm{CO}_{2}$, teor de óleos e graxas e biomassa fúngica, em três tempos de avaliação do potencial hidrolítico de Penicillium sp F002 e Rhizomucor sp F018 sobre óleo de soja e escuma de caixa de gordura do restaurante universitário da Universidade Federal do Espírito Santo.

\begin{tabular}{|c|c|c|c|c|c|c|c|c|c|}
\hline \multirow{2}{*}{ Tratamento } & \multicolumn{3}{|c|}{$\begin{array}{c}\mathrm{CO}_{2} \\
\left(\mathrm{mg} \cdot 0,1 \mathrm{~kg}^{-1}\right) \\
\end{array}$} & \multicolumn{3}{|c|}{$\begin{array}{c}\text { O\&G } \\
\left(\mathrm{g} \cdot \mathrm{kg}^{-1}\right)\end{array}$} & \multicolumn{3}{|c|}{$\begin{array}{c}\mathrm{BF} \\
\left(\mathrm{mg} \cdot \mathrm{g}^{-1}\right)\end{array}$} \\
\hline & $10 \mathrm{~d}$ & $20 \mathrm{~d}$ & $30 \mathrm{~d}$ & $10 \mathrm{~d}$ & $20 \mathrm{~d}$ & $30 \mathrm{~d}$ & $10 \mathrm{~d}$ & $20 d$ & $30 \mathrm{~d}$ \\
\hline OS & $78,2^{e}$ & $275,4^{f}$ & $346, O^{f}$ & $58,0^{e}$ & $45,0^{c}$ & $41, \mathrm{O}^{\mathrm{f}}$ & $\mathrm{Nd}$ & $\mathrm{Nd}$ & $\mathrm{Nd}$ \\
\hline OSL & $377,9^{d}$ & $541,7^{c}$ & $613,0^{c}$ & $33,0^{c}$ & $18,0^{\mathrm{a}}$ & $14,7^{b}$ & $\mathrm{Nd}$ & $\mathrm{Nd}$ & $\mathrm{Nd}$ \\
\hline OS FOO2 & $381,4^{d}$ & $448,1^{e}$ & $492,0^{e}$ & $35,0^{c d}$ & $31,0^{b}$ & $31,0^{e}$ & $4,05^{c}$ & $5,4 \mathrm{O}^{\mathrm{f}}$ & $6,1^{c}$ \\
\hline OS L FOO2 & $399,7^{c}$ & $499,0^{d}$ & $567,4^{d}$ & $23,0^{b}$ & $19,7^{a}$ & $19,5^{c}$ & $7,04^{b}$ & $8,20^{d}$ & $9,91^{b}$ \\
\hline OS F018 & $380,8^{d}$ & $440,8^{e}$ & $492,3^{e}$ & $36,7^{d}$ & $29,7^{b}$ & $28,3^{d}$ & $4,37^{c}$ & $5,92^{e}$ & $6,14 c$ \\
\hline OS L F018 & $481,9^{b}$ & $611,0^{b}$ & $701,2^{b}$ & $18,0^{a}$ & $14,0^{a}$ & $13,7^{b}$ & $10,02^{\mathrm{a}}$ & $12,46^{\mathrm{b}}$ & $13,30^{\circ}$ \\
\hline OS F002 F018 & $523,1^{\mathrm{a}}$ & $648,7^{a}$ & $740,0^{a}$ & $17,3^{a}$ & $13,0^{a}$ & $10,0^{a}$ & $10,56^{a}$ & $12,91^{a}$ & $13,63^{a}$ \\
\hline ECG-RU & $215,5^{g}$ & $329,7^{9}$ & $362,4^{g}$ & $59,3^{f}$ & $46,7^{c}$ & $41,7^{f}$ & $\mathrm{Nd}$ & $\mathrm{Nd}$ & $\mathrm{Nd}$ \\
\hline ECG-RU L & $479,8^{d}$ & $642,4^{c}$ & $704,8^{c}$ & $29,0^{c}$ & $15,3^{\mathrm{a}}$ & $14,0^{\mathrm{bc}}$ & $\mathrm{Nd}$ & $\mathrm{Nd}$ & $\mathrm{Nd}$ \\
\hline ECG-RU FOO2 & $353,9^{f}$ & $408,2^{f}$ & $446,7^{\dagger}$ & $35,0^{d}$ & $30,7^{b}$ & $30,0^{e}$ & $4,51^{c}$ & $4,31^{e}$ & $4,70^{e}$ \\
\hline ECG-RU L FOO2 & $501,3^{c}$ & $598,3^{d}$ & $665,8^{d}$ & $22,3^{b}$ & $17,7^{\mathrm{a}}$ & $16,7^{c}$ & $8,48^{b}$ & $9,04^{d}$ & $11,03^{\mathrm{d}}$ \\
\hline ECG-RU F018 & $374,7^{e}$ & $426,9^{e}$ & $466,0^{e}$ & $38,7^{\mathrm{e}}$ & $27,3^{b}$ & $26,3^{d}$ & $4,57^{c}$ & $4,71^{e}$ & $5,14^{e}$ \\
\hline ECG-RU L FO18 & $626,2^{b}$ & $760,6^{b}$ & $806,2^{b}$ & $19,0^{\mathrm{ab}}$ & $13,0^{\mathrm{a}}$ & $11,7^{\mathrm{ab}}$ & $12,52^{a}$ & $13,22^{b}$ & $14,52^{\mathrm{b}}$ \\
\hline ECG-RU F002 F018 & $659,1^{\mathrm{a}}$ & $807,4^{a}$ & $864,0^{a}$ & $17,3^{\mathrm{a}}$ & $13,0^{a}$ & $10,0^{a}$ & $12,86^{a}$ & $14,12^{\mathrm{a}}$ & $15,27^{\mathrm{a}}$ \\
\hline
\end{tabular}

O\&G: teor de óleos e graxas; BF: biomassa fúngica; OS: óleo de soja; L: lipase comercial; ECG-RU: escuma de caixa de gordura do restaurante universitário da Universidade Federal do Espírito Santo; FOO2: fungo Penicillium sp; FO18: fungo Rhizomucor sp; ab.,c.e.fg médias seguidas por letras iguais, no âmbito dos conjuntos separados pela linha transversal, não diferem significativamente pelo teste de Tukey ( $p=0,05)$; Nd: não determinada. 
de triglicerídeos, surfactantes, óleos vegetais, resíduos oleosos industriais ou seus produtos de hidrólise apresentam capacidade indutora, conforme Turki (2013). No presente trabalho, o óleo de soja e a escuma de caixa de gordura constituíram indutores oleosos de atividade lipásica, portanto hidrolítica, e também como fontes de carbono, para os fungos analisados. O consumo dessas fontes carbonáceas hidrolisadas, principalmente quanto ao seu conteúdo lipídico, serviu como importante variável (remoção de óleos e graxas) para estimar o potencial hidrolítico dos isolados Penicillium sp. F002 e Rhizomucor sp. F018 (Figura 3 e Tabela 3).

A areia e a vermiculita utilizadas como suporte aos substratos oleosos hidrolisados, simulando solo natural, por serem minerais inertes não constituíram fontes de nutrientes para os fungos avaliados, possibilitando inferir que os valores obtidos para as três variáveis analisadas advieram do potencial intrínseco constitutivo (genético) dos mesmos. Os fatores não constitutivos com possível influência em relação ao potencial hidrolítico apresentado pelos dois fungos foram as condições ambientais de incubação e o meio mínimo mineral utilizado (composição química bem definida), idênticos para todos os tratamentos experimentais, fato que contribuiu para a facilitação da reprodução, repetição e confiabilidade.

\section{CONCLUSÕES}

A utilização conjunta dos meios de cultura sólidos $\mathrm{MB}$ e $\mathrm{MMOS}_{\mathrm{R}}$, indicadores de atividade lipásica extracelular e intracelular, respectivamente, evitou perdas por escape de isolados, pela impossibilidade ou deficiência de detecção da atividade lipásica em um deles, na etapa de pré-seleção, partindo-se de um considerável número (cem isolados) obtido das diferentes fontes utilizadas. No meio MB foram detectados crescimento e atividade lipásica para o isolado Penicillium sp. F002 e não para o isolado Rhizomucor sp. F018. No meio $\mathrm{MMOS}_{\mathrm{R}}$, ocorreu o inverso, e Rhizomucor sp. F018 destacou-se como o de maior crescimento da biomassa, dentre todos com reação positiva para atividade lipásica intracelular, nesse meio de cultura.

O IE foi útil para a quantificação da atividade lipásica extracelular, permitindo a seleção do isolado Penicillium sp. F002, pelo maior valor apresentado para essa variável dentre os isolados avaliados. A hidrólise do óleo de soja e da escuma de caixa de gordura serviu à afirmação do perfil de atividade lipásica dos isolados Penicillium sp. F002 e Rhizomucor sp. F018, credenciando-os a pesquisas subsequentes para utilização em processos de tratamento de efluentes oleosos e ou de produção de biodiesel, sendo que o segundo, em função da atividade lipásica intracelular apresentada, como potencial biocatalisador de célula integral a ser utilizado nos citados processos, de forma econômica e ambientalmente viável.

\section{REFERÊNCIAS}

AGUIEIRAS, E.C.G.; CAVALCANTI-OLIVEIRA, E.D.; FREIRE, D.M.G. (2O15) Current status and new developments of biodiesel production using fungal lipases. Fuel, v. 159, p. 52-67.

ALBERTON, D; MITCHELL, D.A.; CORDOVA, J.; PERALTA-ZAMORA P.; KRIEGER, N. (2010) Production of a fermented solid containing lipases of Rhizopus microsporus and its application in the pre-hydrolysis of a high-fat dairy wastewater. Food Technology and Biotechnology, v. 48, n. 1, p. 28-35.

ANDRADE, G.S.S.; FREITAS, L; OLIVEIRA, P.C.; CASTRO, H.F. (2O12) Screening, immobilization and utilization of whole cell biocatalysts to mediate the ethanolysis of babassu oil. Journal of Molecular Catalysis B: Enzymatic, v. 84, p. 183-188

ANDRADE, G.S.; CARVALHO, A.K.; ROMERO, C.M.; OLIVEIRA, P.C.; CASTRO, H.F. (2014) Mucor circinelloides whole-cells as a biocatalyst for the production of ethyl esters based on babassu oil. Bioprocess and Biosystems Engineering, v. 37, n. 12, p. 2539-2548.

APHA - AMERICAN PUBLIC HEALTH ASSOCIATION (2005) Standard methods for the examination of water and wastewater. Baltimore: Port city Press.

BARNET, H.C. \& HUNTER, B.B. (1998) Illustrated genera of imperfect fungi. 4 ed. Saint Paul: APS Press. 218 p.
CAMMAROTA, M.C. \& FREIRE, D.M.G. (2006) A review on hydrolytic enzymes in the treatment of wastewater with high oil and grease content. Bioresource Technology, v. 97, n. 17, p. 2195-2210.

CARVALHO, A.K.F.; FARIA, E.L.P.; RIVALDI, J.D.; ANDRADE, G.S.S.; OLIVEIRA, P.C.; CASTRO, H.F. (2015) Performance of wholecells lipase derived from Mucor circinelloides as a catalyst in the ethanolysis of non-edible vegetable oils under bacth and continuous run conditions. Industrial Crops and Products, v. 67 p. 287-294.

COLEN, G.; JUNQUEIRA, R.G.; MORAES-SANTOS, T. (2006) Isolation and screening of alkaline lipase-producing fungi from Brazilian savanna soil. World Journal of Microbiology and Biotechnology, v. 22 n. 8, p. $881-885$

GRIEBELER, N.; POLLONI, A.E.; REMONATTO, D.; ARBTER, F. VARDANEGA, R.; CECHET, J.L.; DI LUCCIO, M.; OLIVEIRA, D.; TREICHEL, H.; CANSIAN, R.L.; RIGO, E.; NINOW, J. (2O11) Isolation and screening of lipase-producing fungi with hydrolytic activity. Food and Bioprocess Technology, v. 4, n. 4, p. 578-586.

GUTAROWSKA, B. \& ZAKOWSKA, Z. (2009) Mathematical models of mycelium growth and ergosterol synthesis in stationary mould culture. Letters in Applied Microbiology, v. 48, n. 5, p. 605- 610. 
HAMA, S. \& KONDO, A. (2013) Enzymatic biodiesel production: an overview of potential feedstocks and process development. Bioresource Technology, v. 135, p. 386-395.

HANKIN, L. \& ANAGNOSTAKIS, S.L. (1975) The use of solid media for detection of enzyme production by fungi. Mycologia, v. 67, n. 3, p. 597-607.

HASAN, F.; SHAH, A.A.; HAMEED, A. (2009) Methods for detection and characterization of lipases: a comprehensive review. Biotechnology Advances, v. 27, n. 6, p. 782-798.

MENDES, A.A.; CASTRO, H.F.; PEREIRA, E.B.; FURIGO JUNIOR, A. (2005) Aplicação de lipases no tratamento de águas residuárias com elevados teores de lipídeos. Química Nova, v. 28, n. 2, p. 296-305.

MENEZES, M. \& ASSIS, S.M.P. (2004) Guia prático para fungos fitopatogênicos. Recife: Imprensa Universitária UFRPE. 106 p.

MONTGOMERY, H.J.; MONREAL, C.M. YOUNG, J.C.; SEIFERT, K.A. (2OOO) Determination of soil fungal biomass from soil ergosterol analyses. Soil Biology and Biochemistry, v. 32, n. 8, p. 1207-1217.

NAGARAJAN, S. (2012) New tools for exploring "old friends-microbial lipases”. Applied Biochemistry and Biotechnology, v. 168, n. 5, p. 1163-1196.
RODRIGUES, R.C. \& FERNANDEZ-LAFUENTE, R. (2010) Lipase from Rhizomucor miehei as a biocatalyst in fats and oils modification. Journal of Molecular Catalysis B: Enzymatic, v. 66, n. 1-2, p.15-32.

SANDOVAL, G. \& MARTY, A. (2007) Screening methods for synthetic activity of lipases. Enzyme and Microbial Technology, v. 40, n. 3, p. 390-393,

SINGH, A.K. \& MUKHOPADHYAY, M. (2012) Overview of fungal lipase: a review. Applied Biochemistry and Biotechnology, v. 166, n. 2, p. 486-520.

TELES, C.R.; MUNARO, C.J.; CASSINI, S.T.A. (2009) Modelagem da decomposição aeróbia de lodo de esgoto em solos com diferentes texturas. Revista Brasileira de Engenharia Agrícola e Ambiental, v. 13, n. 2. p. 197-203.

TURKI, S. (2013) Towards the development of systems for high-yield production of microbial lipases. Biotechnology Letters, v. 35, n. 10, p. 1551-1560

WATANABE, T. (2002) Pictorial atlas of soil and seed fungi: morphologies of cultured fungi and key to species. 2 ed. New York: CRC Press. 486 p.

WEBSTER, J.; WEBER, R.W.S. (2007) Introduction to fungi. 3 ed. New York: Cambridge University Press. 841 p. 